\title{
Pseudohyperphosphataemia in patients with multiple myeloma
}

\author{
D McClure, L C Lai, C Cornell
}

\begin{abstract}
The phosphate concentrations were measured in 41 patients who had multiple myeloma with paraproteinaemia using four different methods to compare the incidence of pseudohyperphosphataemia. The direct acid/molybdate method produced the highest number of anomalous results. The erroneously high phosphate concentration was attributable to the presence of turbidity in the reaction $\mathrm{mix}$ ture. No association was found between paraprotein type and occurrence of turbidity. The direct acid/molybdate method was unreliable in patients with serum paraproteins and should therefore not be used for the measurement of phosphate concentration in such patients.
\end{abstract}

There have been several reports indicating that serum phosphate concentrations in patients with paraproteinaemia may be erroneously high if the method of phosphate measurement is based on a direct reaction with molybdate in an acid medium. ${ }^{1-3}$ In this study serum phosphate concentrations were measured in 41 patients with identified serum paraproteins by four different methods to assess the incidence of pseudohyperphosphataemia.

\section{Methods}

Serum samples from patients with multiple myeloma ( $n=41$ ) who had serum paraproteins identified by electrophoresis and typed by immunofixation had serum phosphate measured by four different methods, three of these being on a Cobas Mira analyser and the fourth on a Technicon SMAC. Paraprotein concentration was determined by integration of the electrophoretic peak area using a Corning 720 Scanning Densitometer (Ciba Corning Diagnostics Limited, Halstead, Essex, England).

\section{METHOD 1}

This is a direct method using ammonium heptamolybdate $(3.0 \mathrm{mmol} / \mathrm{l})$ in sulphuric acid $(0.89 \mathrm{mmol} / \mathrm{l})$, based on the method of Daly and Ertinghausen. ${ }^{4}$ Absorbence was measured at $340 \mathrm{~nm}$ (reference range: $0.65-1.3 \mathrm{mmol} /$ 1).

\section{METHOD 2}

A modification of the molybdate method was used with the addition of albumin and formate, as described by Bakker et al. ${ }^{2}$ Absorbence was measured at $340 \mathrm{~nm}$.
METHOD 3

This is an enzymatic method in which the phosphate ions react with inosine in the presence of nucleoside phosphorylase to produce ribose-1-phosphate and hypoxanthine. The latter is oxidised to xanthine then to uric acid, and the hydrogen peroxide formed measured as the quinoneimine product when it reacts with 4-aminophenazone. Absorbence was measured at $550 \mathrm{~nm}$. The reagents were obtained as a pack from Miles Ltd, Stoke Court, Stoke Poges, Buckinghamshire.

METHOD 4

The method used on the Technicon SMAC is based on that used by Daly and Ertinghausen, ${ }^{4}$ modified by Amador and Urban for the Technicon SMAC. ${ }^{5}$ This instrument requires a dialysis step to remove proteins. Absorbence was measured at $340 \mathrm{~nm}$ (reference range: $0.8-1.44 \mathrm{mmol} / \mathrm{l}$ ).

The data obtained were not normally distributed but logarithmic transformation resulted in acceptable normalisation of the data. The paired $t$ test was used to analyse log transformed phosphate concentrations between different pairs of methods for samples where turbidity was noted to be present in one or more methods. The unpaired $t$ test was used to compare log transformed paraprotein concentrations between turbid samples and nonturbid samples. Correlations between phosphate and paraprotein concentrations in the turbid and non-turbid groups were assessed using $\log$ transformed data. $\chi^{2}$ analysis was used to test the association between paraprotein type and turbidity.

\section{Results}

The table shows the phosphate concentrations measured by the four different methods where turbidity was noted in one or more methods (denoted by an asterisk). The mean of the log transformed phosphate concentrations measured by method 1 was significantly higher than the means of similarly transformed data obtained by the other methods used ( $p<0.02$ in all cases) for the 12 patients (table). The corresponding phosphate concentrations for the remaining 29 patient samples where turbidity was absent were comparable among the different methods used (data not shown): three of these 29 samples had high phosphate concentrations by all four methods and were from patients with renal failure, when hyperphosphataemia is expected to be present. 
Phosphate analysis in patients with multiple myeloma

\begin{tabular}{llllll}
\hline \multicolumn{5}{l}{ Phosphate (mmolll) } & \\
\cline { 2 - 5 } Case & \multicolumn{3}{l}{ Method } & & \\
number & 1 & 2 & 3 & 4 & Paraprotein $(g / l)$ \\
\hline 1 & $1.46^{\star}$ & 1.35 & 1.35 & 1.47 & 2 \\
2 & $2.43^{\star}$ & 1.24 & 1.21 & 1.35 & ND \\
3 & $1.59^{\star}$ & 0.94 & 0.94 & 1.00 & 21 \\
4 & $1.78^{\star}$ & 1.41 & 1.40 & 1.60 & 18 \\
5 & 1.18 & $1.56^{\star}$ & 1.60 & 1.08 & 2 \\
6 & $7.95^{\star}$ & 1.09 & 1.07 & 1.24 & 40 \\
7 & $1.90^{\star}$ & 0.74 & 0.78 & 0.86 & 28 \\
8 & $1.93^{\star}$ & 0.91 & 0.93 & 1.14 & 55 \\
9 & $2.53^{\star}$ & 0.85 & 0.89 & ND & 59 \\
10 & $3.39^{\star}$ & 1.84 & 1.93 & ND & 64 \\
11 & $1.86^{\star}$ & 1.16 & 1.24 & 0.99 & 11 \\
12 & $1.04^{\star}$ & $1.59^{\star}$ & 1.07 & ND & 11 \\
\hline
\end{tabular}

${ }^{\star}$ Indicates the presence of turbidity; ND: Not done.

Method 1: direct acid/molybdate

2: albumin/formic acid

3: enzymatic

These were excluded from any statistical analyses.

The paraprotein concentrations in the "turbid" group ( $n=11$ ) ranged between $2 \mathrm{~g} / \mathrm{l}$ and $64 \mathrm{~g} / 1$ with a median of $21 \mathrm{~g} / 1$, while the paraprotein concentrations in the "non-turbid" group $(n=22)$ ranged between $2 \mathrm{~g} / \mathrm{l}$ and $37 \mathrm{~g} / \mathrm{l}$ with a median of $10 \mathrm{~g} / \mathrm{l}$. Paraprotein had not been quantified in four samples in the "non-turbid" group and the three patients with renal failure were also excluded. The mean of the $\log$ transformed paraprotein concentrations for the "turbid" group was significantly higher than the mean of the "nonturbid" group ( $p<0.01)$.

A positive correlation was found between $\log _{10}$ [phosphate] analysed by method 1 and $\log _{10}$ [paraprotein] in the "turbid" group $(\mathrm{n}=11, \mathrm{r}=0.604, \mathrm{p}<0.05)$. No correlation was found between these parameters in the "non-turbid" group $(n=22)$.

There was no association between paraprotein type and occurrence of turbidity.

\section{Discussion}

The erroneous phosphate results produced by the direct acid/molybdate method were probably due to turbidity in the reaction mixture. This turbidity may have been due to a physical property of the paraprotein concerned which results in precipitation of the paraprotein under the reaction conditions, although this does not seem to be a property of all paraproteins. A high total protein in the absence of a paraprotein does not produce any turbidity (unpublished observation) by the four methods in this study.
It is interesting to note that the "turbid" group had paraprotein concentrations which were generally higher than those of the "nonturbid" group. Furthermore, there was a positive correlation between log transformed paraprotein and phosphate concentrations in the "turbid" group. The importance of these findings is unclear because of the small numbers present in the "turbid" group but does suggest that the higher the paraprotein concentration the greater the likelihood of pseudohyperphosphataemia.

Although the direct acid/molybdate method gave the highest number of anomalous results, the albumin/formic acid method produced a turbid reaction mixture in two of the specimens (samples 5 and 12). The enzymatic method showed no evidence of turbidity in any of the samples tested. A dialysis step is an integral part of the Technicon SMAC method. Hence paraprotein precipitation does not occur with this method.

Turbidity was observed in 12 out of the 41 samples analysed which is a higher proportion (29\%) than the $10 \%$ reported by Bakker et al. ${ }^{2}$ This may be attributable in part to slight differences in the reaction conditions. Although the albumin/formic acid method was reported by Bakker et $a l^{2}$ to be free from this form of interference, the results of this study indicate otherwise.

In conclusion, the finding of a high phosphate concentration in a patient with multiple myeloma should be interpreted with caution. The direct acid/molybdate method is unsuitable for use in such patients and phosphate measurements in patients with multiple myeloma should be determined by an enzymatic method or by techniques which incorporate prior removal of protein-for example, dialysis.

We thank Mr Ian Gibb, top grade biochemist, Department of Clinical Biochemistry, Royal Victoria Infirmary, Newcastle upon Tyne, for carrying out the Technicon SMAC analyses.

1 Weinberg J, Adler AJ. Spurious hyperphosphataemia in patients with dysglobulinaemia. Miner Electrolyte Metab 1989;15:185-6.

2 Bakker AJ, Bosma H, Christen PJ. Influence of monoclonal immunoglobulins in thret different methods for inorganic phosphorus. Ann Clin Biochem 1990;27:227-31.

3 Sonnenblick M, Eylath U, Brisk R, Eldad C, Hershko C. Paraprotein interference with colorimetry of phosphate in serum of some patients with multiple myeloma. Clin Chem 1986;32:1537-9.

4 Daly JA, Ertinghausen G. Direct method for determining inorganic phosphate in serum with the "Centrifichem". inorganic phosphate in serum

5 Amador E, Urban J. Simplified serum phosphorus analyses by continuous-flow spectrophotometry. Clin Chem 1972;18:601-4. 